PRAXIS

ecucativa

Universidad Nacional de La Pampa

Facultad de Ciencias Humanas

Instituto de Ciencias de la Educación

para la investigación interdisciplinaria

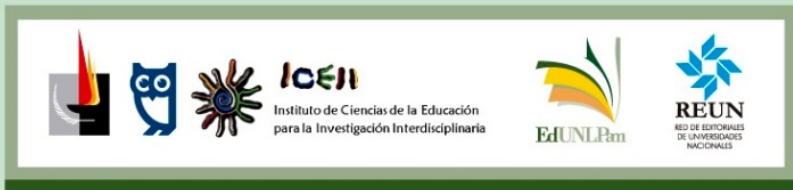

ISSN 2313-934X

SANTA ROSA, LA PAMPA, ARGENTINA

Correo electrónico: iceii@humanas.unlpam.edu.ar

Disponible en https://cerac.unlpam.edu.ar/index.php/praxis

Repensar el diseño estético del espacio escolar. Una "pregunta infinita" con eco en el desarrollo profesional docente. Artículo de Ana Márquez-Román y Encarnación Soto Gómez. Praxis educativa, Vol. 25, No 3 septiembre - diciembre 2021. E - ISSN 2313-934X. pp. 1-24. https://dx.doi.org/10.19137/praxiseducativa-2021-250304

Esta obra se publica baja Licencia Creative Commons 4.0 Internacional CC BY-NC-SA Atribución, No Comercial, Compartir igual

(c) (P) $\$$

\title{
Repensar el diseño estético del espacio escolar. Una "pregunta infinita" con eco en el desarrollo profesional docente
}

Rethinking the aesthetic design of school space. An "infinite question" with echo in teacher professional development

Repensar a concepção estética do espaço escolar. Uma "questão infinita" com eco no desenvolvimento profissional dos professores

\section{Ana Márquez-Román}

Universidad de Málaga, España

marquezr@uma.es

https://orcid.org/0000-0003-2486-8827

\section{Encarnación Soto Gómez}

Universidad de Málaga, España

esoto@uma.es

https://orcid.org/0000-0001-5758-1684

Recibido: 2021- 02-12 | Revisado: 2021-04-30 | Aceptado: 2021-05-07 


\section{Resumen}

¿Qué delatan los espacios escolares sobre nuestra imagen de infancia y de educación? A menudo, las aulas de Educación Infantil presentan una estética anacrónica e infantilizada que refleja la imagen que los docentes tienen acerca de las capacidades infantiles. Este artículo pretende abrir caminos para la consideración de la belleza del espacio como parte del conjunto de variables que condicionan el proceso educativo y, en concreto, la reconstrucción del conocimiento práctico de los docentes que se encargan de su diseño. Se presenta para ello un estudio de caso' que pretende comprender la experiencia de reflexión y transformación pedagógica, espacial y personal vivida por un grupo de maestras de Educación Infantil de un centro público de Málaga (España). Los resultados señalan la potencialidad de esta reflexión y transformación metodológica-espacial para el cuestionamiento de las propias ideas y actuaciones docentes, reforzando prácticas más coherentes con sus principios teóricos.

Palabras Claves: espacio educativo; estética; desarrollo profesional docente; conocimiento práctico; teorías proclamadas y teorías en uso

\section{Abstract}

What do school spaces reveal about our image of childhood and education? Early Childhood Education classrooms often present an anachronistic and infantilized aesthetics that reflects the image that teachers have about children's capacities. This article intends to open ways for the consideration of the space beauty as a variable that conditions the educational process and, specifically, the reconstruction of the practical knowledge of the teachers who are in charge of its design. For this purpose, a case study is presented which aims to understand the experience of reflection and pedagogical, spatial and personal transformation lived by a group of Early Childhood Education teachers from a public center in Malaga (Spain). The results indicate the potentiality of this reflection and methodological-spatial transformation for the questioning of the teaching ideas and actions, reinforcing practices that are more consistent with their theoretical principles.

Keywords: educational space; aesthetic; teacher professional development; practical knowledge; proclaimed theories and theories in use

\section{Resumo}

O que revelam os espaços escolares sobre a nossa imagem da infância e da educação? Muitas vezes, as salas de aula dos jardins de infância apresentam uma estética anacrónica e infantilizada que reflete a imagem que os docentes têm quanto às capacidades das crianças. Este artigo pretende abrir caminhos para a consideração da beleza do espaço como parte do conjunto de variáveis que condicionam o processo educativo e, especificamente, para a reconstrução dos saberes práticos dos docentes responsáveis pelo seu design. Nesse sentido, apresenta-se um estudo de caso que visa compreender a experiência de reflexão e transformação pedagógica, espacial e pessoal vivida por um grupo de educadores de infância de um centro público de Málaga (Espanha). Os resultados indicam o potencial desta reflexão e transformação metodológica-espacial para o questionamento de ideias e ações docentes, reforçando práticas mais consistentes com os seus princípios teóricos.

Palavras-chave: espaço educativo; estética; desenvolvimento profissional docente; conhecimento prático; teorias proclamadas e teorias em uso. 


\section{Introducción}

Cada uno de los actos que conforman nuestro desarrollo profesional docente están estrechamente unidos a nuestras concepciones y creencias educativas: las conscientes y, sobre todo, las inconscientes (Pérez Gómez, 2012). El modo en que presentamos una actividad, en que preparamos el espacio del aula, los materiales que elegimos, el modo en que nos relacionamos con el alumnado... todo habla de nuestra imagen de infancia, de nuestra imagen de docente $y$, por supuesto, de nuestra imagen de educación (Trueba, 2015).

En este sentido, el diseño estético del espacio educativo adquiere un papel fundamental al tratarse de uno de los factores clave que hace visible las concepciones pedagógicas que orientan la práctica cotidiana de los maestros y maestras. Es decir, los espacios se convierten en el escaparate de su conocimiento práctico o teorías en uso, a menudo distantes de sus teorías proclamadas (Argyris, 1993). No es extraño así que, con frecuencia, docentes que defienden la idea de un niño y niña libre propongan, al mismo tiempo, espacios altamente estructurados.

En esta investigación, nos centramos en describir y analizar la relación que existe entre las cualidades estéticas del espacio escolar y el conocimiento y pensamiento práctico de los docentes implicados en un proceso de innovación educativa. Es decir, pretendemos describir la posible relación entre los principios pedagógicos, explícitos e implícitos, que sostienen y orientan los factores estéticos (espacios, áreas verdes, mobiliario, objetos, imágenes, colores, sonidos, olores, iluminación...) que las maestras y maestros ponen en práctica en sus aulas, con su conocimiento práctico y pensamiento práctico. Así como el lugar que ocupan estos procesos en el proyecto de innovación educativa que están desarrollando.

A lo largo de este artículo, intentaremos dar respuesta a estas cuestiones a través de la comprensión del proceso de transformación vivido por un grupo de maestras de Educación Infantil de un colegio público de Málaga (España). Una transformación inicialmente superficial donde empiezan a desaparecer las pizarras y la excesiva presencia de mesas y sillas estructuradas que recuerdan a la imagen de una escuela tradicional y académica, para dar paso progresivamente a la aparición de disposiciones espaciales más abiertas y menos saturadas, a través de la organización del espacio en ambientes de aprendizaje diferenciados que promueven el desarrollo flexible de diferentes saberes y lenguajes (Riera Jaume et al., 2014).

\section{Revisión teórica}

\section{La necesaria búsqueda de la belleza: un factor cultural y biológico. La estética cotidiana}

Jean Piaget estudió la naturaleza desde el punto de vista cultural y ofreció ideas interesantes acerca de cómo el entorno influye en las personas. A partir del estudio de las transformaciones que se producen en los seres vivos cuando cambian de lugar, descubrió que derivado de estas exposiciones medioambientales diversas, en pocas generaciones, se daban grandes cambios de comportamiento, de la estructura del cerebro e incluso del ADN. Es decir, Piaget identificó el desarrollo cognitivo como una reorganización progresiva donde la maduración biológica se 
relaciona directamente con la experiencia ambiental. Sin embargo, aunque Piaget rechaza la tesis de la prevalencia del ADN en el desarrollo, tampoco habla de un determinismo del medio ambiente. Él señala que no hay una relación directa de causa-efecto entre el organismo y el medio, sino que hay una relación de coacción entre los dos: el desarrollo histórico-social no se detiene y esto cambia de nuevo el lugar. Otras veces, el medio cambia y las personas cambian para adaptarse (Delgado, 2017). Tanto Piaget como Vygotski convergieron en adoptar premisas constructivistas e interaccionistas que explican que el conocimiento se construye como producto de la actividad del sujeto en su interacción con el medio ambiente físico y social (Rodríguez Arocho, 1999). Y "entender la complejidad de esta interacción es requisito imprescindible para nuestras descripciones, explicaciones y prescripciones pedagógicas" (Pérez Gómez, 2020, p. 6).

Como plantean Murris et al. (2018), en el contexto actual, es inspirador el enfoque del posthumanismo crítico desarrollado por Haraway, Barad y Braidotti, sustentado, en gran medida, en los planteamientos de Gilles, Deleuze y Guattari, en diálogo con los filósofos occidentales Platón, Leibniz, Kant, Nietzsche y Spinoza. Especialmente reveladora es la útil distinción que Haraway (2016) hace para definir a los animales humanos como sistemas autopoiéticos y sistemas simpoiéticos. En los primeros, los humanos se entienden como unidades organizativas cerradas, autónomas, controladas centralmente (por ejemplo, a través de una voluntad o intelecto humano), orientadas al crecimiento y "desarrollado con". Por el contrario, la simpoiesis significa "hacer-con". Parte de la idea de que nada se hace a sí mismo y es una palabra propia de los sistemas complejos, sistemas que carecen de límites, evolutivos e impredecibles.

Barad (2007) complementa esta idea con el sugerente concepto de intra-acción, un proceso donde los individuos se construyen desde el principio en virtud de las relaciones y contextos que habitan. La intracción se diferencia de la interacción en que la naturaleza y la cultura nunca son puras, nunca se dejan de afectar mutuamente, sino que siempre están en relación, un sistema simbiótico para Haraway, un enredo para Barad, y un ensamblaje para Deleuze.

Los individuos no preexisten a sus interacciones, sino que son el producto de tales intrarrelaciones entrelazadas. El sistema vivo complejo que denominamos seres humanos solo puede comprenderse entonces como efecto de esta compleja dinámica de relaciones inter e intra permanentemente presentes en su evolución filo y ontogenética (Pérez Gómez y Soto, 2021). Como ya confirman las investigaciones en neurociencia y epigenética (Lipton, 2016; Esteller, 2017; Church, 2019), la génesis sociocultural del cerebro y de la mente destaca la interdependencia continua del cerebro y las mediaciones culturales que lo conforman en un proceso abierto, incierto y vulnerable de recreación permanente. Nuestros genes, como ya avanzaba Piaget, no son los que determinan nuestro destino, lo posibilitan, constituyen un caudal ilimitado de posibilidades a la espera de que los distintos estímulos del contexto físico, biológico, psicológico y social, desde el comienzo de la vida, vayan activando (encendiendo) y desactivando (apagando) aquellos más adecuados para responder a los requerimientos de dicho entorno. El diálogo entre el interior y el exterior es continuo e intenso a lo largo de todas las fases del desarrollo humano (Dispenza, 2015, citado en Pérez Gómez, 2020). 
Estas conclusiones nos parecen relevantes para el tema que aquí se aborda pues, si entendemos que cultura y biología se condicionan mutuamente, podemos pensar que algunas elecciones y gustos estéticos - que hasta ahora considerábamos puramente culturales y subjetivospueden condicionar la expresión de los genes y, por tanto, la estructura epigenética del ser humano.

Nuestra propia naturaleza, determinada por la experiencia cultural y el consecuente proceso evolutivo de la humanidad, nos lleva a decantarnos por determinados patrones espaciales; de esta manera, al igual que nos sentimos naturalmente atraídos por sabores dulces frente a sabores amargos - pues para nuestros antepasados era la única forma de diferenciar un alimento seguro de un alimento venenoso-, también nuestro instinto vital nos hace orientarnos por determinadas proporciones, texturas, luces, colores... que nos facilitan nuestra (super)vivencia. Como ya decía el filósofo romano Cicerón:

Existe, de hecho, jueces, una ley no escrita, sino innata. La cual no hemos aprendido, heredado, leído, sino que de la misma naturaleza la hemos agarrado, exprimido, apurado. Ley para la que no hemos sido educados, sino hechos; y en la que no hemos sido instruidos, sino empapados. (Extremoduro, 2008)

De este modo, podríamos decir que hemos arrancado y extraído de la propia naturaleza algunas características estéticas del medio como: la simetría, la unidad, la línea, el ritmo o la armonía propia de las plantas, de los ríos o los mares. Características que parecen unirnos a toda la especie humana, a pesar de las evidentes diferencias que cada uno de nosotros y, en especial, cada grupo cultural tiene en relación con el gusto estético. Características que parecen considerarse, de manera generalizada, placenteras y favorables para el bienestar y el desarrollo humano.

En este mismo sentido, Bachelard, en su libro La poética del espacio (2000), reflexiona sobre la casa onírica o casa de nuestros sueños. Como es evidente, las características de la casa onírica están condicionadas culturalmente, sin embargo, y como decíamos, la imagen también parece reflejar unas constantes universales de la mente humana (Pallasmaa, 2018). La sociedad moderna ha intentado eliminar esa imagen onírica. Nuestra obsesión por lo nuevo y lo no tradicional, nos ha llevado a crear espacios "estetizados" que carecen de raíces en nuestra experiencia natural y existencial. Espacios saqueados de nuestras más profundas dimensiones bioculturales.

Resulta necesario entonces diferenciar entre "estética" y "estetización". La estética, a diferencia de la estetización, no es un ornamento, sino un sentimiento y actitud. Es la capacidad de sentir, percibir y responder mediante los sentidos a todo el entorno que nos rodea (Feeney y Moravcik, 1987; Callejón y Yanes, 2012). En palabras de Vea Vecchi, en su prólogo al libro de Hoyuelos (2004):

La estética es una actitud cotidiana, empática y sensible con el entorno, un hilo que conecta las cosas entre sí, un aire que lleva a preferir un gesto a otro, a seleccionar un objeto, a elegir un color, un pensamiento; elecciones en las que se percibe armonía y cuidado, placer para la mente y para los sentidos. (p. 15) 
La estética es un "sentir sensible", es lo opuesto a la indiferencia, a la conformidad y a la desvinculación con el entorno. La estética asume una función de encuentro "con", una actitud de cuidado y atención a lo que hacemos, al detalle, a lo bello, a todo lo que se conoce, y a todo lo que se está por conocer. Es la capacidad de maravillarse, de sorprenderse en la relación con el otro y con lo otro. Y si entendemos que necesitamos maravillarnos para aprender, podemos asumir que sin estética no hay conocimiento y que, sin estética, no hay educación.

Sin embargo, la estética no siempre ha sido concebida desde esta perspectiva tan amplia. La estética es un complejo y controvertido término que nace en la antigua Grecia bajo el vocablo filocalía (amor a la belleza), y que durante décadas ha estado ligada exclusivamente a lo que podemos denominar como "arte museístico".

Fue en 1983 cuando la noción de estética se extiende a otros contextos al aparecer por primera vez el término estética cotidiana, acuñado por Josehp Kupfer, quien sugirió experimentar la vida diaria como si de una experiencia artística se tratara. Más adelante, Katya Mandoki (1994) conceptualiza este término, cobrando, a partir de aquí, un creciente interés que se derivó en la creación de una subdisciplina de la estética analítica en la que se plantea que "las actividades desvinculadas del arte o la naturaleza pueden tener propiedades estéticas y hacer surgir experiencias estéticas significativas" (Irvin, 2009, p. 137).

A diferencia de la filosofía del arte, la estética cotidiana se ocupa así de la percepción de los colores, olores, sonidos y texturas que están presentes en la mesa del desayuno, en nuestras ropas, el camino hacia el trabajo, o nuestros espacios educativos, entre otros (Mandoki, 1994, 2006; Saito, 2007; Leddy, 2012; Pérez-Henao, 2014; Marini et al., 2018).

A menudo, la estética cotidiana ha sido considerada como un tema banal, superficial, sin importancia para el desarrollo humano. Esto puede deberse, en primer lugar, a que nuestra formación nos ha llevado a valorar principalmente aquellos factores que pueden medirse de manera objetiva, ignorando todo lo que no puede ser valorado a través de la lógica, la razón, la memoria, u otras muchas habilidades a las que Read (2011) se refiere como fetiches intelectuales. $Y$, en segundo lugar, quizás, porque el carácter (principalmente) subjetivo de la estética espacial puede llevarnos a pensar que "todo vale" y que, por tanto, ninguno de los elementos que la conforman necesitan de reflexión y de un contraste fundamentado.

Por todo ello, pensamos que es necesario reivindicar una reorganización estética de la educación. Una reorganización en el sentido de buscar un equilibrio más justo entre la actividad intelectual y la instintiva, siendo esta última la que está directamente vinculada a la sensibilidad estética, porque "la racionalidad sin sensibilidad ni empatía, como la imaginación sin cognición ni racionalidad, crean un conocimiento humano parcial, incompleto" (Vecchi, 2013, p. 60). En este mismo sentido, señala Errázuriz (2015) que "una educación de calidad debería procurar un desarrollo más equilibrado y coherente de los diversos lenguajes y modos de conocer (visuales, sonoros, espaciales, entre otros)" (p. 23). 
Es necesario acompañar el proceso educativo de modo que se impulse $y$, sobre todo, no corrompa la sensibilidad estética del individuo, procurando un desarrollo más equilibrado, coherente y comprometido.

\section{La consideración del espacio y su estética como variable educativa. Los ambientes de aprendizaje}

Marini et al. (2018) señalan que "posiblemente el entorno escolar construido sea la materia primera más común y accesible a todos los estudiantes, profesores y directivos desde la cual indagar la estética cotidiana" (p. 363). Un descubrimiento que viene acompañado de un creciente interés en la estética del entorno educativo, a pesar de que la preocupación de las administraciones públicas por la estética del espacio continúa siendo prácticamente nula (Baker, 2012).

Gariboldi (2011) reivindica la consideración del espacio como recurso educativo, señalando dos motivos principales por los que se está dando un creciente interés en la estética del entorno escolar. En primer lugar, por la consolidación de un enfoque pedagógico, en particular en la escuela infantil, que otorga importancia al juego, a los procesos de autoorganización cognitiva de los niños y niñas y al papel indirecto que ejerce el docente en la gestión ambiental. En segundo lugar, por el progresivo desarrollo en las últimas décadas de un enfoque ecológico y sistémico para entender el desarrollo infantil, que encuentra una de sus principales referencias en la obra de Bronfenbrenner (2002), y por el cual se concibe el comportamiento humano, en convergencia con los aportes del movimiento posthumanista señalado, como el resultado de un intercambio recíproco entre las características del individuo y el medio, lo que implica que los factores físicos y sociales sean determinantes en los procesos de aprendizaje del niño y la niña.

Desde esta perspectiva, por tanto, el espacio ya no es simplemente un telón de fondo, sino un jugador clave en el proceso educativo. Los espacios donde los niños y niñas se mueven, los objetos con los que juegan, el tipo de imágenes que observan o el modo en que estas se colocan tienen un poder nada inocente que a menudo tendemos a ignorar. Un poder que, a pesar de estar siempre presente ante nuestros ojos, se oculta muchas veces a nuestra consciencia.

A partir de estos planteamientos, Margolis (1999) acuña la famosa noción de currículum visible, pero oculto, refiriéndose con ello a que la organización ambiental actúa de forma soterrada, sin que los individuos se den cuenta. De la misma forma, Bernstein (1975) se refería a ello bajo el término pedagogía invisible, es decir, una pedagogía en la que el educador no controla explícitamente al niño o niña, sino que interviene organizando el ambiente en vez de desarrollar estrategias educativas más dirigidas destinadas a la adquisición de unas competencias determinadas.

El cuidado del entorno se convierte entonces en una de las más imperiosas obligaciones de los adultos respecto a la educación de la infancia. Esto es, la obligación de convertirnos, como propone Trueba (2015), en espaciohablantes. Porque el espacio no es algo muerto o neutral, sino 
que está lleno de mensajes que hablan y expresan nuestras intenciones educativas y nuestra imagen de infancia.

A lo largo de la historia de la Educación Infantil, se han desarrollado propuestas que basan buena parte de su filosofía pedagógica y organizativa en la importancia del espacio: experiencias como las escuelas Montessori, Waldorf, las escuelas infantiles de Reggio Emilia, el Centro Internacional Pestalozzi, o el Martinet y las Escuelas Municipales Infantiles de Pamplona en España son algunos ejemplos de ello.

Las aportaciones de estas experiencias han servido de inspiración para muchas escuelas de todo el mundo (entre las que se encuentra la escuela del estudio aquí presentado), consolidándose en ellas una filosofía educativa en la que el espacio se abre y organiza facilitando el encuentro, la experimentación y la interrelación. Esto es, una redistribución del espacio por ámbitos de experiencia y no por niveles, que supone que la idea de grupo-clase como hasta ahora la concebimos se diluya, pudiendo el alumnado de diferentes edades compartir experiencias y momentos en diferentes espacios a los que se les llama ambientes. Ambientes que no se asemejan a las habituales aulas, sino que se tratan de espacios con sugerentes propuestas que les permiten desarrollarse sin tener que ser constantemente asistidos (aunque sí acompañados) por un adulto; espacios que permiten el "encuentro con" y el "hacer con" del que hablábamos anteriormente; espacios que facilitan al niño y niña entrar en contacto con lo demás y los demás, desde sí, encontrando sus propias formas de aprender. Todo ello a través de un cuidado especial de los diferentes factores estéticos: del mobiliario, los materiales, las imágenes, así como de la luz, el color, el olor o el sonido. Espacios complejos, armónicos, vibrantes, acogedores y seductores que han de pensarse para cada contexto y en relación con las personas que lo habitan y el momento social en el que vivimos. Espacios inconformistas que permiten asombrarnos, maravillarnos y aprender. Espacios, en definitiva, estéticamente educativos.

\section{El diseño estético del espacio educativo: una ventana al conocimiento práctico docente}

El diseño estético del espacio educativo está fuertemente determinado por la cultura escolar y, por consiguiente, por los criterios pedagógico-didácticos de cada centro. Se tratan de elecciones supeditadas a las decisiones, ideas y posiciones, más o menos conscientes, que los docentes tienen acerca de la infancia, la enseñanza, el aprendizaje y la vida escolar (Knauf, 2019). El espacio educativo, por tanto, se convierte en un factor clave que hace visible las concepciones pedagógicas que orientan la práctica cotidiana de los maestros y maestras.

En la investigación que aquí se presenta, se ha pretendido indagar en estas decisiones, ideas y posicionamientos, abordando la posible relación entre diseño estético espacial y el desarrollo del conocimiento práctico docente, entendido este como el conjunto de conocimientos, habilidades, valores, actitudes y emociones que operan de manera automática y que condicionan nuestra percepción y actuación (Soto et al., 2015).

Consideramos de especial importancia realizar este análisis ya que, a pesar de que en las últimas décadas se han dado grandes cambios en las ideas explícitamente mantenidas por los 
docentes, en relación con el proceso educativo, estos cambios no parecen haberse trasladado, en la misma medida, a la práctica de las aulas, dando lugar a que nuestras escuelas no se diferencien hoy mucho de lo que fueron hace años (McNeil y Borg, 2018).

Todo ello se debe a que el conocimiento de los docentes que diseñan estos espacios va más allá de un saber técnico o disciplinar. Es un saber ligado a la vida, fruto de la exposición reiterada a determinados escenarios y situaciones de aprendizaje en los que se repiten ciertos patrones, y donde buena parte de sus representaciones cotidianas, incluidas las que se refieren al aprendizaje y a la enseñanza, se adquieren de manera inconsciente, sin pretenderlo (Pozo et al., 2006). Esto es el conocimiento práctico antes definido, también denominado conocimiento tácito (Polanyi, 1967) o conocimiento en la acción (Schön, 1994), un conocimiento aprendido de forma espontánea, y que resulta útil y eficaz para actuar con eficacia y rapidez ante las situaciones que se nos presentan, habitualmente cargado de prejuicios, lagunas y contradicciones, aunque susceptible de transformación a través de la reflexión consciente.

Así, y como veremos en los resultados de nuestra investigación, a menudo los profesores actúan contrariamente a lo que creen que es correcto (Korthagen, 2010), ya que este conocimiento práctico, a menudo derivado de toda una cultura escolar muy arraigada y aprendida durante sus años de discentes, se conforma por automatismos cerebrales difíciles de detectar y cambiar al permanecer por debajo de la conciencia, dando lugar con demasiada frecuencia a distancias significativas entre lo que piensan, dicen, sienten y hacen. Esto es, distancias entre sus teorías proclamadas y sus teorías en uso (Argyris, 1993). De esta forma, a pesar de aprender durante su formación inicial y permanente una serie de teorías más relacionadas con el aprendizaje autónomo y activo, cuando se enfrentan a la práctica emergen esta serie de automatismos antagónicos.

No resulta extraño escuchar entonces que se hable de favorecer la exploración y experimentación, cuando la gran mayoría de materiales no están al alcance de los niños y niñas; de potenciar la autonomía del alumnado, mientras encontramos lavabos no adaptados o mobiliario inapropiado para la edad a la que se dirigen; o que se hable de favorecer el proceso de relación y socialización, en espacios muy estructurados orientados fundamentalmente al trabajo individual (Riera Jaume, 2005). "A menudo no somos conscientes de haber aprendido a hacer estas cosas; simplemente las hacemos" (Schön, 1994, p. 54).

Se hace necesaria, por tanto, una reflexión sobre la propia práctica que permita transformar el conocimiento práctico en pensamiento práctico (Soto et al., 2015). Esto es, un pensamiento que no solo incluya el conocimiento en la acción, sino también el conocimiento reflexivo sobre esa acción. Un pensamiento constituido por todos los recursos (conscientes e inconscientes) que utilizamos cuando intentamos comprender, diseñar e intervenir en una situación concreta de manera más lenta y racional (Soto et al., 2021).

En este marco, las preguntas de nuestra investigación se agrupan en torno a dos ejes:

1. Descripción y análisis del conocimiento práctico del grupo de docentes del estudio: ¿cuáles son los principios pedagógicos que sostienen y orientan las concepciones espaciales de las maestras y maestros?, ¿qué relación existe entre sus teorías declaradas 
y su conocimiento práctico en relación con los factores estéticos del espacio escolar (áreas verdes, mobiliario, objetos, imágenes, colores, sonidos, olores, iluminación...)?

2. Innovación, espacio y transformación del conocimiento práctico: ¿qué lugar ocupan los cambios estéticos y espaciales del aula en los procesos de innovación educativa?, ¿qué cambios metodológico-espaciales se están desarrollando y de qué manera estos cambios se relacionan con el desarrollo de su pensamiento práctico?, ¿cómo deconstruir automatismos inconscientes?, ¿preguntarnos y repensar la belleza de nuestros espacios educativos puede suponer (o no) una movilización de nuestras creencias y conocimientos pedagógicos?

En definitiva, y como expusimos en la presentación de este artículo, el foco de nuestra investigación pretende analizar la relación que existe entre las cualidades estéticas del espacio escolar y el conocimiento y pensamiento práctico (Soto et al., 2015; Pérez Gómez, 2017) de un grupo de docentes implicadas en un proceso de innovación educativa.

\section{Metodología de la investigación}

Con el objetivo de dar respuesta a las preguntas propuestas y conocer la vinculación existente entre el diseño estético del espacio y el desarrollo del conocimiento práctico de los docentes, desarrollamos un estudio de caso sobre la experiencia de innovación que un grupo de maestras de Educación Infantil habían puesto en marcha y donde el espacio educativo y su estética empezó a cobrar valor y sentido, desarrollando en sus aulas transformaciones espaciales que, a su vez, parecen tener repercusiones en sus concepciones sobre la infancia, el rol docente y todo el proceso educativo.

Conocer esta realidad educativa supone tener en cuenta por tanto la diversidad de concepciones y valoraciones personales, conscientes e inconscientes, que cada participante aporta al tema en cuestión, situándonos ante un foco de estudio que no puede medirse de forma objetiva, sino que, por el contrario, ha de recuperar la experiencia vivida y sentida por los actores, y que está por tanto medido subjetivamente por cada sujeto y la subjetividad social (Flores, 2015).

El enfoque cualitativo y, en concreto, el estudio de caso (Stake, 2010; Stenhouse, 1980) aparece en este contexto como el más adecuado, pues busca hacer una aproximación global de las situaciones sociales para explorarlas, describirlas y comprenderlas de manera inductiva, es decir, a partir de los significados, principios, creencias, intenciones y otras características no directamente manifiestas de las personas que las viven (Barreto, 2007).

\section{Contextualización del caso y muestra de la investigación}

El contexto en el que se desarrolla la investigación es el C.E.I.P. Frida Kahlo, 'situado en un pueblo costero de la provincia de Málaga (España), y se concentra concretamente en los tres cursos que conforman el Segundo Ciclo de Educación Infantil. 
La población que participa en este estudio se conforma de los 12 miembros implicados en dicho ciclo: el equipo docente conformado por nueve maestras (tres del grupo de tres años, tres del grupo de cuatro, dos del grupo de cinco y una maestra de apoyo), y el equipo directivo (la jefa de estudios y el director del centro).

La elección del caso se realizó mediante el procedimiento de muestreo teórico o intencionado, considerando este un caso interesante por los siguientes motivos:

- El desarrollo de una metodología basada en ambientes de aprendizaje. La aproximación al aprendizaje en este centro ha cambiado y está cambiando, de manera que el modelo de enseñanza tradicional centrado en el profesor está siendo reemplazado por un modelo centrado en el alumnado, con énfasis en la construcción libre del conocimiento. Esto da lugar a un contexto que resulta interesante de conocer por ser bastante atípico dentro de lo que es habitual en un centro escolar público en España.

- La manifestación de un interés estético por parte de las maestras. En este contexto, se empieza a incorporar igualmente la importancia de la dimensión estética como uno de los ejes del proyecto, dándonos esto la oportunidad de obtener datos de relevancia al permitir observar cómo las declaraciones explícitas de las docentes se empiezan a relacionar con la construcción de los nuevos espacios.

\section{Recogida y análisis de la información}

Tal y como señalan Pérez Gómez et al. (2015), adentrarnos en el conocimiento práctico de los docentes requiere atender mucho más que las manifestaciones verbales de estos, pues la teoría proclamada no es suficiente para describir su práctica, sino que es más una defensa, o racionalización de la misma. Por ello, hemos fortalecido y prestado especial atención a la observación concreta de los espacios y prácticas entre el abanico de técnicas utilizadas para la recogida de datos, pues es precisamente la observación de esta práctica real de las maestras la que ofrece información relevante sobre dicho conocimiento práctico. Dichas técnicas fueron, por tanto:

- la observación y análisis fotográfico en profundidad de la realidad física de los ocho ambientes de aprendizaje;

- la observación y documentación pedagógica de la actuación del equipo docente;

- la observación, grabación y análisis de reuniones de ciclo y charlas explicativas sobre el proyecto, impartidas por el equipo docente y directivo;

- grupo de discusión semiestructurado con el equipo docente;

- análisis de los documentos institucionales del centro.

El diario de campo e investigación, con la incorporación de imágenes, se convirtió además en un instrumento clave para dar cuenta narrada de lo vivido, registrar, evidenciar y analizar la experiencia.

Siguiendo con el planteamiento de Taylor y Bogdan (1994), el análisis de la información se llevó a cabo en cuatro niveles: a) codificación de la información, recopilando y seleccionando todo el material bruto (documentos, notas de campo, fotografías, transcripciones, etc.); b) categorización 
de los datos, reorganizando los datos seleccionados en una serie de categorías y subcategorías que agruparan los datos por afinidad temática; c) enunciado de hechos, formulando proposiciones para cada categoría, relativas a los significados que los propios informantes atribuyen a sus acciones o a los elementos del medio investigado, o elaboradas por el investigador para dar unidad a determinados datos que guardaran puntos en común; d) informe y resultados de la investigación, elaborando a partir de las proposiciones anteriores modelos explicativos que describieran lo más fielmente posible la realidad investigada. Así, el conjunto de categorías y subcategorías derivadas del estudio fueron:

\section{Tabla 1}

Tabla de las categorías y subcategorías analizadas en el estudio

\section{Concepción y valoración explícita de la estética del espacio educativo}

- Formación recibida, en relación con la estética del espacio educativo

- Concepción de los diferentes elementos del espacio. Criterios y referentes estéticos

- El espacio global

- El mobiliario

- Los materiales

- Paredes puertas y ventanas. Las imágenes

- Los suelos y techos

- El paisaje sonoro y cósmico

- Valoración de la estética

- Por su repercusión en el estilo de enseñanza (ambientes de aprendizaje)

- Por su repercusión en el aprendizaje del alumnado

\section{Intervención en la organización del espacio educativo y su estética}

- El aspecto de los ambientes en los que desarrollan su labor educativa

- Cambios estéticos realizados

- Distribución del poder de intervención sobre el espacio

- Insatisfacción con el aspecto estético de los ambientes. Conciencia de la necesidad de mejora e implicación en dicha mejora

- Dificultades en el diseño estético de los ambientes

- Falta de espacio disponible

- Falta de recursos económicos

- Falta de tiempo 


\section{- Falta de estabilidad \\ - Falta de libertad y autonomía \\ - Inexistencia de un proyecto común \\ - Falta de concienciación. Dificultad para romper con ciertos hábitos \\ - Falta de responsabilidad iniciativa e implicación por parte de las docentes \\ - Facilidades en el diseño estético de los ambientes}

\section{Resultados}

\section{La historia de una escuela que se transforma. Los primeros pasos}

La historia del contexto seleccionado merece una mención especial por su importancia en la presente investigación.

Como toda historia, esta también tiene un comienzo, y es la visita de dos maestras de este centro al colegio público El Martinet, en Ripollet (Barcelona). Inspiradas por la belleza de esta escuela catalana y su concepción sobre el enseñar y el aprender, las docentes inician la transformación de su práctica hacia modelos más activos y libres, donde el espacio escolar pasa a convertirse en espacio educativo (Acaso, 2018; Ceppi y Zini, 2009; Charteris et al., 2017; López, 2021; Nair, 2014), entendiendo educativo como ese proceso que ayuda a crecer de forma autónoma, crítica y creativa (Pérez Gómez, 2012, 2017).

Esta historia de cambio se inicia así en el curso escolar 2013/2014, cuando las aulas de cinco años $A$ y $B$ se unieron para compartir un proyecto común, disfrutando el alumnado de los recursos espaciales, temporales y materiales que se organizaron en ambas aulas y pudiendo relacionarse como un gran grupo clase. Al siguiente año, fueron tres aulas del nivel de tres años y una de cuatro las que disfrutaron de este proyecto. $Y$ tras dos años de experiencia, todas las aulas de infantil participaron en el desarrollo de ambientes de aprendizajes promoviendo el libre tránsito del alumnado entre ellos más allá de su aula de referencia. Esta experiencia evidencia cómo el cambio y la mejora educativa puede ser promovida por iniciativas singulares como la de estas dos docentes que consiguieron ilusionar y comprometer al resto de sus compañeras con un nuevo imaginario de infancia y, por tanto, con nuevas formas de enseñanza y aprendizaje.

Tras cuatro años de experiencia, los espacios del Segundo Ciclo de Educación Infantil de este centro presentan una organización completamente diferente a la habitual, dejando de ser aulas con 25 mesas y sillas donde estar sentados y en silencio, para ser sustituidos por ambientes que ofrecen un sinfín de posibilidades para aprender en compañía de los iguales, de adultos o en solitario (Figura 1). Estos son: el ambiente de naturaleza y sensorial; el ambiente lógico-matemático; de construcciones; lectura y escritura; juego simbólico; teatro; pintura; y modelado. Ambientes que no son independientes, sino que se abren para conformar entre todos un único espacio: el de la escuela. 


\section{Figura 1}

Algunos de los ambientes de aprendizaje del Segundo Ciclo de Educación Infantil. Izquierda-arriba: ambiente de teatro; derecha-arriba: ambiente de pintura; izquierda-abajo: ambiente de lectura y escritura; derecha-abajo: ambiente de juego simbólico.
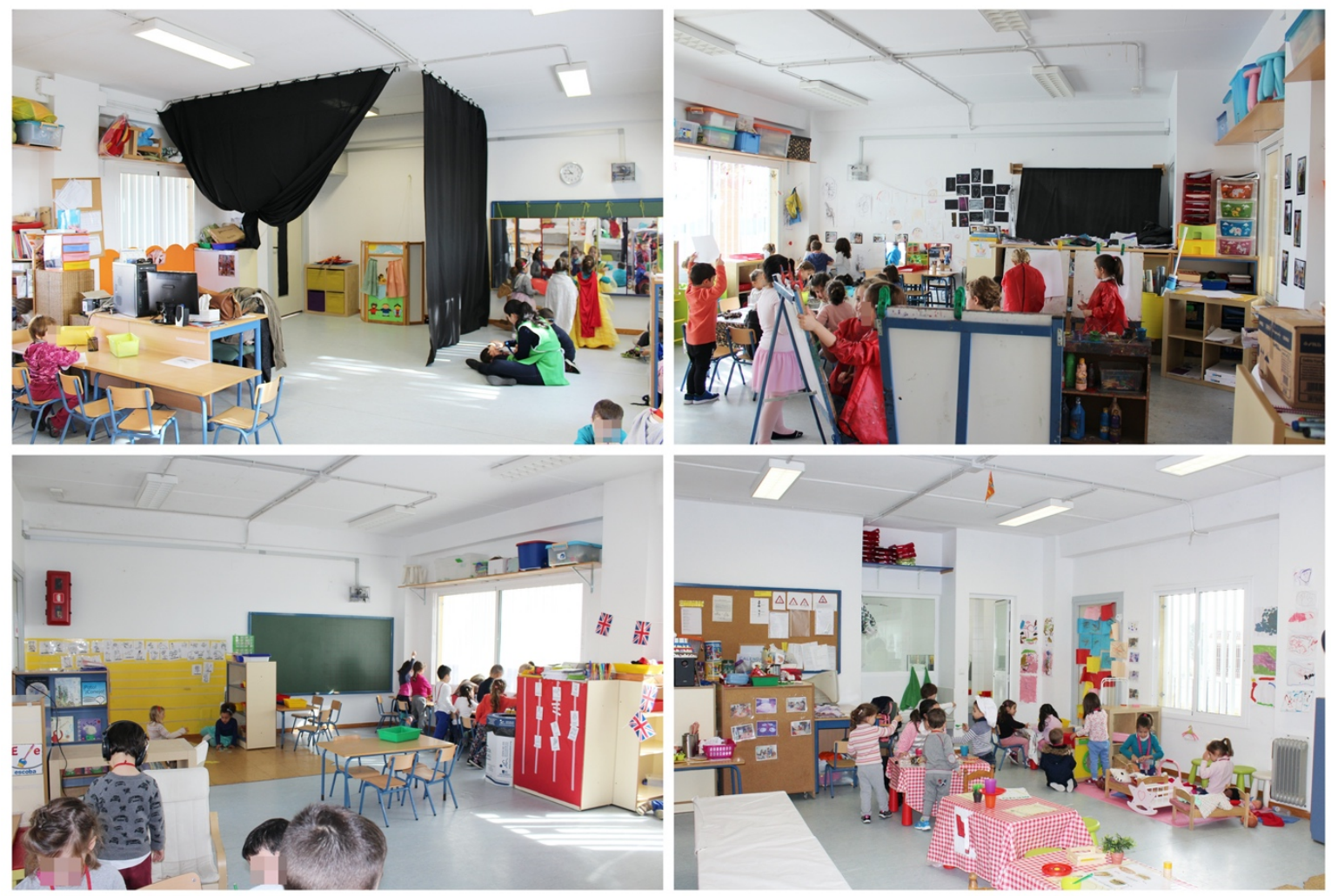

\section{Análisis previo. Teorías proclamadas y teorías en uso de las docentes respecto a la estética de los ambientes de aprendizaje. Distancias, lagunas y disonancias}

Desde el primer día que visitamos la escuela, percibimos cómo las maestras se sienten partícipes y comprometidas con este proceso de transformación metodológica y espacial. La sensación inicial es que la organización del espacio y su estética es una cuestión que a las docentes les preocupa, considerando así la mejora de los ambientes como uno de sus objetivos: "Ha habido una evolución en la estética porque realmente cuando hemos hablado siempre hemos pensado que es una mejora que necesitamos" (Gabriela, tutora de sala de cuatro años. Grupo de discusión, 2016).

Sin embargo, ¿cómo empiezan a considerar la estética un aspecto a tener en cuenta en el desarrollo de su proyecto? Atendiendo a sus respuestas, los motivos pueden resumirse en dos:

- Por su repercusión en el estilo de enseñanza elegido. Para las docentes, existe una relación entre el estilo de enseñanza y la organización del espacio, de manera que para ellas esta variable parece adquirir sentido especialmente cuando toman la decisión de 
desarrollar una metodología activa, la cual exige una reorganización del espacio que satisfaga nuevas prioridades como el desarrollo de la autonomía o el aprendizaje entre iguales: "Una educación innovadora requiere un ambiente diferente al de una clase tradicional. Sería muy difícil tener aquí las 25 mesas y sillas y hacer actividad libre. Estarían entorpeciendo" (Gabriela, tutora de sala de cuatro años. Grupo de discusión, 2016).

- Por su repercusión en el aprendizaje del alumnado. Un cambio en la enseñanza conlleva inevitablemente a transformar los procesos de aprendizaje. Así, y de la misma forma, consideran que la estética es uno de los muchos factores que propicia la creación de un clima de aula más atractivo, confortable y acogedor que estimula el aprendizaje del alumnado:

Por ejemplo, en el ambiente matemático, cuando se pusieron las alfombras y se quitaron mesas, el ambiente era como más fluido, más natural. Yo creo que a ellos y a mí nos produjo un cambio interesante, una forma de jugar diferente. (Tania, tutora de sala de cuatro años. Grupo de discusión, 2016)

Estas y otras primeras evidencias nos ayudan a dibujar desde lo declarado algunos de los criterios estéticos de las docentes: la existencia de un equilibrio en todo el ambiente, la sencillez en los espacios, el uso de colores menos estridentes, la preferencia por aquellos materiales naturales y reciclados, o el orden de los mismos.

Sin embargo, la observación del aspecto que presentan los ambientes de aprendizaje aporta otros matices al discurso. Es un escaparate privilegiado de sus teorías en uso o conocimiento práctico, donde en algunos casos aparecen ciertas disonancias:

- Sobre la naturaleza de los recursos; en los diferentes ambientes, aún persiste mobiliario y enseres de plástico, con estampados infantilizados y colores estridentes que contrasta con la inclinación de las docentes hacia los materiales naturales (Figura 2): "Sobre todo la estética de colores naturales, que no sea estridente para los niños, que no sean muy infantilizados... en el que el niño es persona, no 'el niño chico'" (Gabriela, tutora de sala de cuatro años. Grupo de discusión, 2016).

\section{Figura 2}

Naturaleza de los recursos
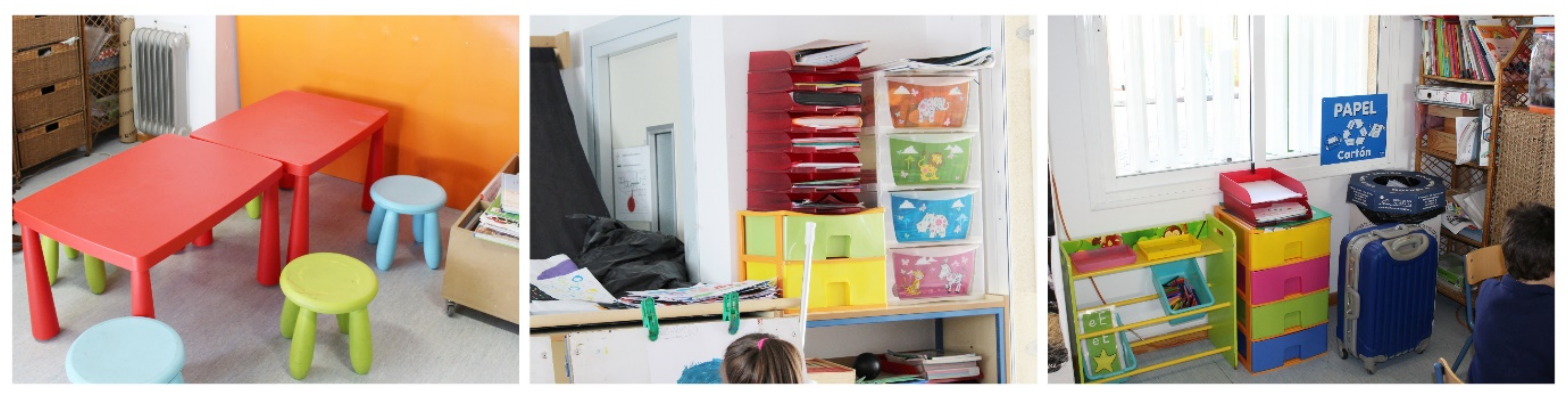
- Sobre la coherencia pedagógica de los recursos; como notas discordantes, todavía tienen presencia en las aulas elementos como la pizarra, la mesa del profesorado y el tablón de noticias (Figura 3), recursos útiles en una pedagogía de la homogeneidad, del discurso y de la disolución del individuo frente al grupo.

\section{Figura 3}

Coherencia pedagógica de los recursos
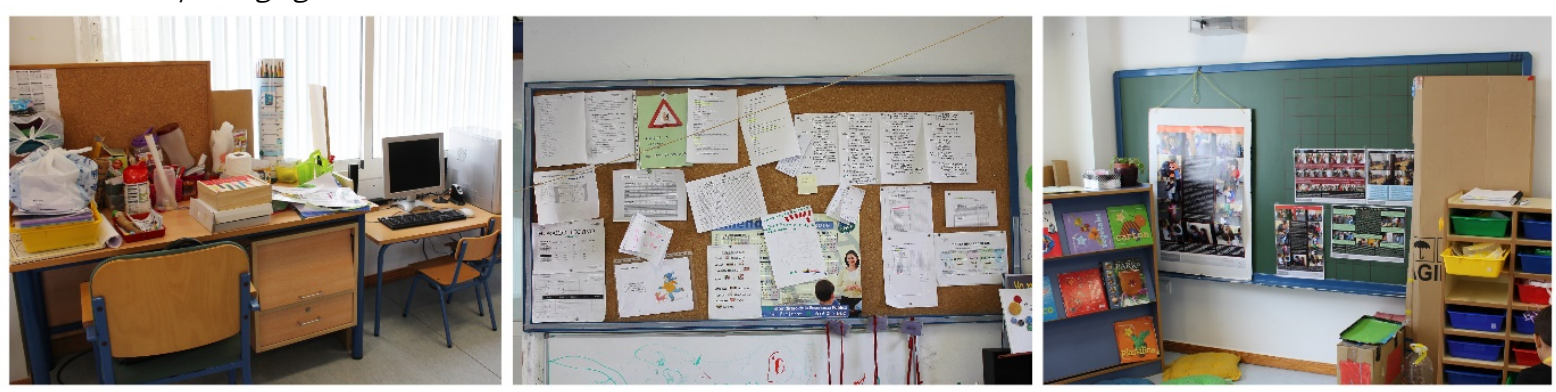

- Sobre la armonía del espacio y los recursos, las mejores intenciones estéticas se encuentran en muchas ocasiones limitadas por el peso de la historia de los centros escolares y la consecuente acumulación de recursos (Figura 4) que difícilmente encuentran un acomodo ordenado, bello y armónico con los nuevos hábitats que se quieren crear: "Yo la estética la veo muy relacionada con el orden, con que cada cosa tenga su lugar y se pueda acceder a ella" (Sonia, tutora de sala de cinco años. Grupo de discusión, 2016).

\section{Figura 4}

Armonía del espacio y los recursos
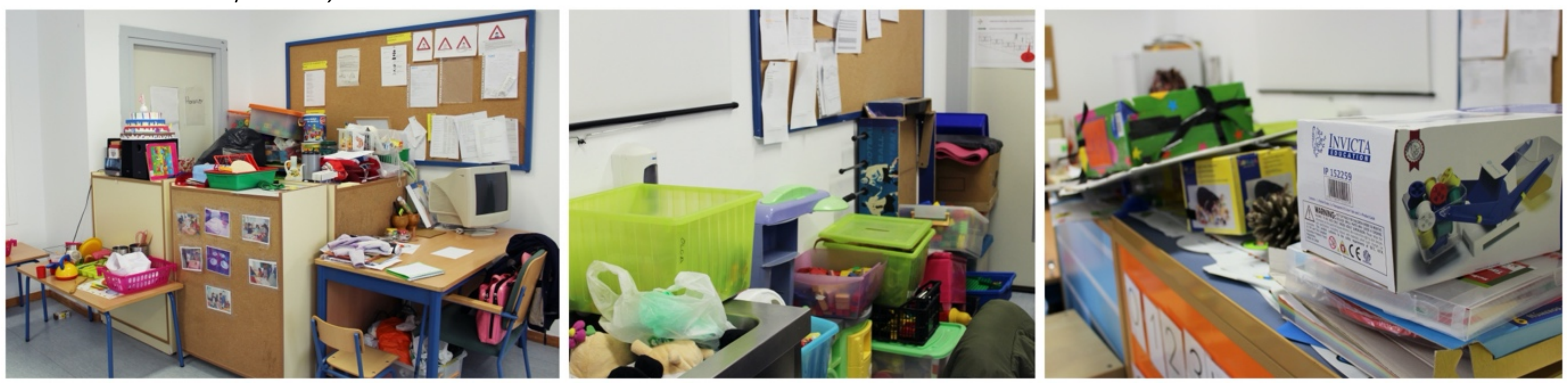

- Sobre la imagen estereotipada de infancia; todavía algunas paredes del aula se visten con imágenes de la industria dedicada a la producción de material escolar y que a grandes rasgos se reconoce por el diseño tipo caricaturesco e infantilizado. Cierto es, sin embargo, que esta realidad no es predominante y coexiste con una nueva sensibilidad: "En la escuela, sobre todo en Infantil, siempre se ha infantilizado todo, muñecajos de Maestra de Infantil, ${ }^{i}$ todo con colores muy chillones... y es todo lo contrario" (Laura, tutora de sala de cuatro años. Grupo de discusión, 2016). 
- Sobre la emergencia difusa de la nueva imagen de infancia; en esta convivencia entre lo viejo y lo nuevo, aparece de forma tímida un papel protagonista de la infancia, con la exposición de trabajos realizados por el alumnado que no persigue la copia o reproducción mimético de un modelo, así como de fotografías que los muestran y reconocen en los diferentes ambientes, aunque aún queda un camino por recorrer para acomodar estas producciones de una forma respetuosa y cuidada en el ambiente (Figura 5).

\section{Figura 5}

Emergencia difusa de la nueva imagen de infancia
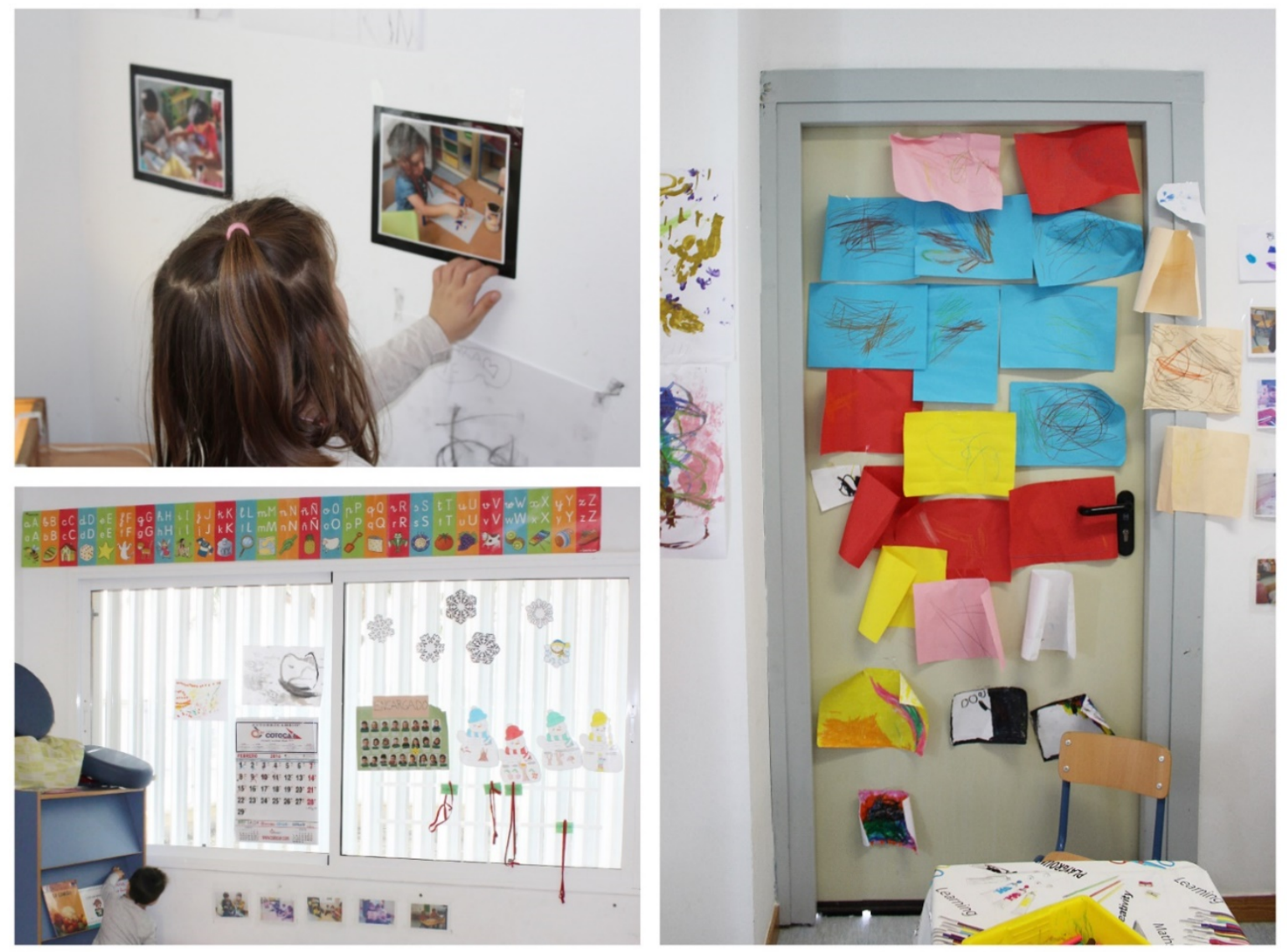

- Sobre la saturación y el vacío, en los diferentes espacios, aparece cierta acumulación, con cierto eclecticismo e impulsividad en la selección y distribución de las imágenes. No aparecen muchos espacios vacíos, "neutros", o libres de estímulos visuales.

Esta convivencia diversa, y en cierto modo contradictoria, de criterios y prácticas, podrían evidenciar la complejidad del proceso de reconstrucción del conocimiento práctico y cómo el tránsito de las teorías declaradas a las teorías en uso ha de enfrentarse tanto a la resistencia de las 
creencias propias como a las dificultades institucionales y contextuales para desocupar y reinventar los espacios escolares como veremos a continuación.

\section{La transformación y reflexión sobre la estética espacial: un proceso emocional, vibrante, removedor del conocimiento práctico docente}

Cada uno de los elementos descritos, la convivencia acrítica de recursos de naturaleza y coherencia pedagógica diversa, la saturación y proliferación desordenada de objetos y producciones del alumnado, nos muestran la huella y el tránsito de las maestras de la escuela heredada a la escuela deseada. Y es que el aspecto de los ambientes antes descrito, tal y como las mismas docentes señalan y reconocen, presentan en parte el legado de la escuela tradicional que vivieron y promovieron durante muchos años. Un pasado muy reciente y presente aún.

Sin embargo, no podemos obviar, tal y como ellas manifiestan, que este proceso de innovación convive con una escasa flexibilidad y apoyo por parte de la Administración educativa. De ahí que son numerosas las dificultades que obstaculizan el desarrollo de esta escuela soñada: la inestabilidad en la plantilla docente, las ratios que impiden la promoción de la pareja pedagógica, la falta de recursos económicos, la falta de tiempo o, más concretamente, la insuficiencia de espacio de almacenamiento para el material oficial, que provoca la acumulación de materiales propios de la metodología anterior, así como la presencia de mobiliario en desuso: "Ahí es donde se ve el tránsito de la [metodología] tradicional a esta. 0 sea, el cambio, de repente te ves con mucho material de antes que es como... mil cosas repetidas" (Marisol, tutora de sala de tres años. Grupo de discusión, 2016).

Más allá de las dificultades contextuales, la presencia o no de los criterios estéticos que declaran, no acaban de tomar cuerpo en su conocimiento práctico o piloto automático (Pérez Gómez, 2012). Las docentes son conscientes de que desarrollan gran parte de sus funciones bajo este piloto automático, es decir, bajo una serie de automatismos que funcionan de manera constante sin la necesidad de la conciencia (Duhigg, 2012). Solo cuando el contexto cambia de modo radical (como es el cambio de metodología hacia una que da más protagonismo a la infancia) nos vemos forzados a considerar lo que antes ni siquiera veíamos:

Nosotras caemos en el día a día. Dejas eso ahí y dices "ahora lo quito" y como el día es tan intenso, aunque te vayas a las tres menos cuarto, sigue estando eso encima (...). Nos falta un poco la rutina de nosotras mismas organizarnos, de romper lo tradicional, que era dejar las cosas encima de la mesa (...). Digamos que es un aprendizaje. Yo no soy capaz como otras personas de hacer "pum" y romper. Yo tengo una rutina, la cual tengo que ir poco a poco mejorando y trabajándola (...). No es algo innato, es una cosa que queremos estar pendiente pero que tenemos tan asimilado, es algo tan automático, algo que tenemos dentro, que se convierte en rutina. Y hay que cambiarla, como otras muchas. (Tania, tutora de sala de cuatro años. Grupo de discusión, 2016) 
El conocimiento práctico es un conjunto de hábitos intuitivos que solo podemos transformar en pensamiento práctico incorporando nuevos hábitos informados construidos en procesos reflexivos y en relación con nuevos conocimientos y nuevas prácticas (Korthagen, 2010; Pérez Gómez et al., 2015). En este sentido, las maestras son conscientes tanto de la dificultad de romper con ciertos hábitos como de la necesidad de "desactivarlos", de ponerlos en cuestión: "Es lo que te digo muchas veces de cambiar el 'chip'. Dejo las cosas encima de las mesas porque tengo esa rutina. Es salirse de la rutina" (Tania, tutora de sala de cuatro años. Grupo de discusión, 2016).

Aquí, parece tener un papel importante la propia naturaleza de la estética espacial. Y es que, en nuestra búsqueda de la belleza del espacio, como valor puramente humano que es, resulta necesario no solo atender a la intuición, sino también a nuestro pensamiento lógico. Esto es, a procesos mentales más relacionados con la conciencia como puede ser el de la reflexión y la crítica. Porque situarse en el lado de la belleza es ir siempre a contracorriente de nuestra necesidad de adaptación, es moverse en un continuo estado de inconformidad y reflexión (Márquez-Román, 2019).

En consecuencia, la fenomenología de la arquitectura se basa en verbos más que en sustantivos -el acto de acercarse a casa, no la fachada; el acto de entrar, no la puerta; el acto de mirar por la ventana, no la propia ventana; o el acto de reunirse a la mesa más que esos mismos objetos-, todas estas expresiones verbales parecen disparar nuestras emociones (Pallasmaa, 2018). Y si tenemos en cuenta que el conocimiento práctico es un complejo conjunto de recursos formado por esas emociones, así como por los valores, actitudes, conocimientos y habilidades que se ponen en juego en contextos determinados, la consecuencia lógica es que los entornos y la reflexión sobre ellos adquieren un papel esencial en la constitución de nuestra conciencia. Es decir, generar procesos de reflexión con los docentes sobre el espacio escolar puede ayudar a tomar conciencia de su conocimiento práctico. Un proceso necesario para la transición de dicho conocimiento al pensamiento práctico.

Muestra de ello son también las diferentes percepciones y valoraciones que muestran las maestras sobre la estética espacial, su rol docente, incluso sobre sus concepciones educativas, en función del grado de implicación y el tiempo que cada una de ellas lleva inmersa en esta nueva organización espacial y metodológica. De esta forma, las maestras que llevan más tiempo sienten una especial preocupación por este aspecto, mientras que aquellas que han llegado recientemente al centro consideran la estética como algo secundario:

Lo que menos me ha preocupado al estar en un ambiente era la estética (...). El que llega se fija más en el rol docente, en los ritmos de los niños... y es verdad que la estética es lo último que he dejado en este tiempo. (Sonia, tutora de sala de cinco años. Grupo de discusión, 2016)

Esta situación hace visible el conocimiento práctico de algunas de las maestras implicadas, donde un cambio metodológico de esta naturaleza pone en cuestión los ejes fundamentales de lo que significa para ellas "ser maestra". Un cambio que afecta directamente a su misión docente (Korthagen, 2010). 
La inseguridad e incertidumbre que este nuevo rol les provoca deja en un segundo plano el valor de la estética en el espacio. A medida que las docentes ganan experiencia en esta metodología, y consolidan y naturalizan este nuevo rol, empiezan a valorar elementos como la estética, dejándose contagiar por el interés mostrado por las docentes con mayor experiencia:

Es un cambio tan maravilloso de lo tradicional a esto... lo flipas tanto que, al principio, ni te lo planteas. Es como..., "esto es la caña". No es como..., "necesita mejorar". Luego, ya en las reuniones, hablando con compañeras, ahí ya te das cuenta y lo ves súper importante. Y ya cuando estás en ese punto ya es como..., "la estética", otro paso. (Marisol, tutora de sala de tres años. Grupo de discusión, 2016)

Para estas docentes, la consideración y valoración de la estética es un proceso que requiere tiempo ya que viene ligado a una crisis de pensamientos y creencias muy enraizados sobre el proceso educativo y su papel en él. Y es, en este caso, con la puesta en marcha de una metodología centrada en el juego y la libre experimentación en los ambientes de aprendizaje cuando ellas se replantean su práctica diaria, teniendo progresivamente en cuenta factores que con una metodología tradicional no suelen considerar.

Con todo, podemos decir que esta experiencia de transformación didáctica y espacial les ha llevado a poner sobre la mesa la estética del espacio como ámbito nuevo y estimulante que les ayuda a profundizar en el resto de elementos del proceso educativo, construyendo y consensuando nuevos cambios espaciales y pedagógicos (Figura 6) cada vez más coherentes con su propios ideales y criterios educativos:

Tras una larga charla, deciden entre todos visitar uno por uno los ambientes (...). Quitan las imágenes infantilizadas y estereotipadas que hasta ahora se disponían en las paredes, quitan aquellos trabajos de los niños que se encuentran rotos y que aportaban una sensación de descuido y dejadez, quitan también trabajos de años anteriores que todavía cuelgan de las paredes y del techo, reorganizan algunos muebles y materiales, etc. (Diario de investigación, 2016)

\section{Figura 6}

Transformación del ambiente lógico-matemático
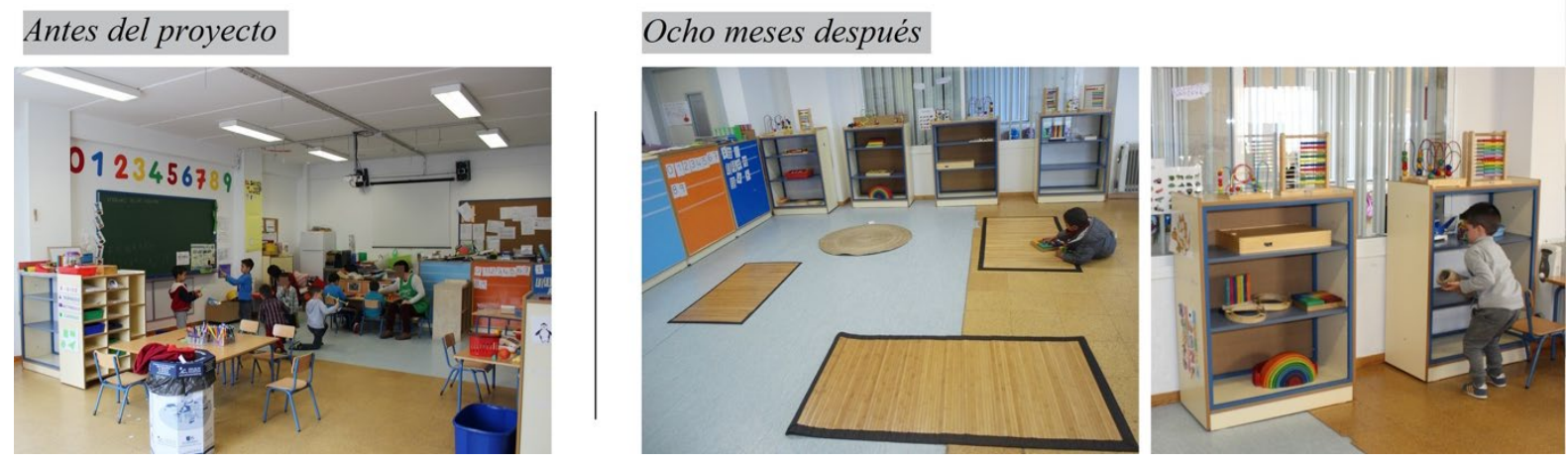
La concepción y valoración estética del espacio se encuentra así en construcción, a la par que se reconstruye el conocimiento práctico de las docentes. Se trata de un andar constante, donde la práctica diaria, la reflexión sobre esa práctica, así como la implicación y el compromiso tienen un papel esencial.

\section{Conclusiones}

Recorrer los ejes que propone este artículo es recorrer el desván del C.E.I.P. Frida Kahlo. Ejes que seguramente merecen una lectura pausada, con la posibilidad de seguir imaginando nuevas alternativas, de seguir imaginando lo que de entrada nos es insospechado, de seguir imaginando, por qué no, que también las escuelas pueden ser de otra manera.

El proyecto de esta escuela es un proyecto que avanza con todo lo que tiene de posibilidad y todo lo que aún está por resolver, con todo lo que tiene de ilusión y al mismo tiempo de inexperiencia, pero, sobre todo, con un deseo y búsqueda constante de una educación cada vez más amable. $Y$ es que el valor del proceso vivido por estas docentes no se ciñe a un simple cambio superficial y de "estetización" del espacio, sino al valiente acto de no caer en el conformismo y la indiferencia. Porque dar valor a los detalles, dar valor a la estética del espacio, es dar valor a la infancia y al proceso educativo. Necesitamos desprender a los espacios de narrativas colonizantes para que puedan nacer las narrativas propias del sujeto que aprende.

A menudo, se habla de la reconstrucción del conocimiento práctico durante la formación inicial de docentes. Sin embargo, y como es lógico, esta reconstrucción también continúa dándose a lo largo de toda la trayectoria profesional. Y aquí es donde hemos venido a detenernos en esta investigación, la cual nos muestra la importancia de la reflexión sobre el diseño de la estética espacial para favorecer la reconstrucción del conocimiento práctico al hacer visible las raíces de las creencias e ideas más inconscientes, procurando así el desarrollo de una filosofía educativa y una forma de ser docente coherente con un proceso realmente educativo.

Se descubre, además, que la naturaleza de la estética del espacio es un factor especialmente poderoso en esta reconstrucción del conocimiento práctico, pues tal y como señala Pallasmaa (2018), la arquitectura opera fundamentalmente en el ámbito preconsciente y corpóreo de nuestra consciencia. Nos enfrenta a cuestiones de identidad y memoria, de lo consciente y lo inconsciente, a los remanentes del comportamiento biológico y de las reacciones y los valores condicionados por la cultura.

Una reflexión sobre la esencia del espacio y de nuestra actuación en él nos aleja por tanto de las propiedades puramente físicas para introducirnos en el territorio psíquico de la mente. $Y$ es desde ahí desde donde podemos tomar conciencia y reconsiderar nuestros modos aprendidos de entender y reaccionar, así como reformular los que consideremos inadecuados para nuestra actuación docente (Pérez Gómez, 2020). Unos modos aprendidos porque, como individuos, nos construimos desde el principio a través de procesos simpoiéticos por el hecho de estar y crecer en relación con los contextos que habitamos en el mundo (Haraway, 2016; Barad, 2007). 
La transformación metodológica y del espacio se convierte entonces en el germen para que estas docentes empiecen a replantearse -en mayor o menor medida- su propia práctica, a reprogramar sus mecanismos cognitivos y emocionales ya automatizados, así como a generar contextos estéticos abiertos a la construcción creativa de los niños y niñas que lo habitan. Un proceso largo donde inevitablemente conviven principios pedagógicos contradictorios, ya que el conocimiento práctico, fortalecido por la experiencia de escuela fundamentalmente academicista que cada docente ha tenido, necesita de procesos lentos de reflexión y acción fundamentada.

No es de extrañar por tanto que, en los próximos años, estos ruidos vayan desapareciendo progresivamente, para dar luz a otros nuevos, a la vez que las maestras se deshacen de sus automatismos y comienzan a replantearse otras variables educativas hasta el momento incuestionables. Porque "la belleza", dice Morelli (2018), "es una pregunta infinita que puede generar el resto".

\section{Notas}

'Investigación financiada por el Ministerio de Universidades del Gobierno de España (FPU 17/04106).

' Los nombres del centro y las maestras participantes son nombres ficticios asignados para salvaguardar su anonimato.

' Conocida revista española de material didáctico.

\section{Bibliografía}

Acaso, M. (2018). Pedagogías invisibles: el espacio del aula como discurso. Los Libros de la Catarata.

Argyris, C. (1993). Knowledge for Action: A Guide to Overcoming Barriers to Organizational Change. Jossey-Bass. Bachelard, G. (2000). La poética del espacio. Fondo de Cultura Económica.

Barreto, M. (2007). Notas sobre investigación e infancia. Infancias Imágenes, 6(1), 34-39.

Bernstein, B. (1975). Classi e pedagogie: visibili e invisibili. En E. Becchi (Ed.), // bambino sociale (pp. 192-224). Feltrinelli.

Bronfenbrenner, U. (2002). La ecología del desarrollo humano. Paidós.

Callejón, M. D. y Yanes, V. (2012). Creación de entornos de aprendizaje en infantil: experiencia estética y juego. Escuela Abierta, 15, 145-161.

Ceppi, G. y Zini, M. (Eds.). (2009). Niños, espacios, relaciones. Metaproyecto de ambiente para la infancia. Red Solare.

Charteris, J., Smardon, D. y Nelson, E. (2017). Innovative learning environments and new materialism: A conjunctural analysis of pedagogic spaces. Educational Philosophy and Theory, 49(8), 808-821.

Church, D. (2019). Mente sobre materia. La asombrosa ciencia de cómo tu cerebro crea la realidad. Arcano Books.

Delgado, M. (2017). Qué nos enseña la biología sobre la arquitectura. Jean Piaget y el cronotopo. Archiimpact. http://archiimpact.com/jean-piaget-y-el-cronotopo/

Duhigg, C. (2012). The power of habit: Why we do what we do in life and business. Random House. 
Errázuriz, L.H. (Ed.) (2015). El (f) actor invisible. Estética cotidiana y cultura visual en espacios escolares. Consejo Nacional de la Cultura y las Artes.

Esteller, M. (2017). No soy mi ADN. RBA Libros.

Extremoduro (2008). La ley innata [CD]. Warner Music.

Feeney, S. y Moravcik, E. (1987). A Thing of Beauty. Aesthetic Development in Young Children. Yooung Children, 42(6), 7-15.

Flores, L. M. (2015). La cuestión del clima y el espacio escolar: lineamientos y proyecciones pedagógicas. En L. H. Errázuriz (Ed.), El (f)actor invisible. Estética cotidiana y cultura visual en espacios escolares (pp. 101-109). Consejo Nacional de la Cultura y las Artes.

Gariboldi, A. (2011). El espacio y su organización. En A. Bondioli, y G. Nigito (Coords.), Tiempos, espacios y grupos. El análisis y la evaluación de la organización en la escuela infantil: DAVOPSI (pp. 99-119). Graó.

Haraway, D. (2016). Staying with the trouble. Duke University Press.

Hoyuelos, A. (2004). La ética en el pensamiento y obra pedagógica de Loris Malaguzzi. Octaedro.

Irvin, S. (2009). Aesthetics of the Everyday. En S. Davies, K. M. Higgins, R. Hopkins, R. Stecker, y D. E. Cooper (Eds.), A Companion to Aesthetics (pp. 136-139). Weley Blackwell.

Knauf, H. (2019). Visual Environmental Scale: Analysing the Early Childhood Education Environment. Early Childhood Education Journal, 47(1), 43-51.

Korthagen, F. (2010). La práctica, la teoría y la persona en la formación del profesorado. Revista Interuniversitaria de Formación del Profesorado, 24(2), 83-101.

Leddy, T. (2012). The Extraordinary in the Ordinary: The Aesthetics of Everyday Life. Broadview Press.

Lipton, B. (2016). La biología de la creencia. La liberación de la conciencia, la materia y los milagros. La Esfera. López, S. (2021). Esencia. Diseño de espacios educativos. Aprendizaje y Creatividad. Ediciones Khaf. Mandoki, K. (1994). Prosaica. Introducción a la estética de lo cotidiano. Grijalbo.

Mandoki, K. (2006). Estética cotidiana y juegos de la cultura. Prosaica I. Siglo XXI.

Margolis, E. (1999). Class Pictures: Representations of Race, Gender and Ability in a Century of School Photography. Visual Sociology, 14(1), 7-38.

Márquez-Román, A. (2019). Dignificar el espacio para dignificar la infancia: El cuidado de la estética del espacio educativo como derecho de los niños y niñas. En A. S. Jiménez Hernández, O. Ghannami, G. Ordaz Olais, K. M. Heredia Guzmán, J. B. Nielsen Niño, L. Lara Vázquez, A. Santos, A. Rique de Alvarenga Ferreira, D. Garcia Galvão, J. Apóstolo, M. A. Martín Sánchez, J. Cáceres Muñoz, y M. A. Conde del Rio (Coords.), La convención sobre los derechos de la infancia a debate 30 años después (pp. 472-485). CIPI Ediciones.

Marini, G., Rodríguez Merchán, J. D. y Salas Aguayo, M. (2018). Estéticas cotidianas escolares: desde lo que se ve hacia cómo se siente la escuela. Educação \& Sociedade, 39(143), 361-378.

McNeil, J. y Borg, M. (2018). Learning spaces and pedagogy: Towards the development of a shared understanding. Innovations in Education and Teaching International, 55(2), 228-238.

Morelli, U. (2010). Mente e bellezza. Arte, creatività e innovazione. Allemandi.

Murris, K., Reynolds, R. y Peers, J. (2018). Reggio Emilia Inspired Philosophical Teacher Education in the Anthropocene: Posthuman Child and the Family (Tree). Journal of Childhood Studies, 43(1), 15-29.

Nair, P. (2014). Blueprint for Tomorrow. Redesigning Schools for Student-Centered Learning. Harvard Education Press.

Pallasmaa, J. (2018). Habitar. Gustavo Gili.

Pérez Gómez, Á. I. (2012). Educarse en la era digital. La escuela educativa. Morata. 
Pérez Gómez, Á. I. (2017). Pedagogías para tiempos de perplejidad. De la información a la sabiduría. Homo Sapiens.

Pérez Gómez, A. I. (2020). Los desafíos educativos en tiempos de pandemias: ayudar a construir la compleja subjetividad compartida de los seres humanos. Praxis educativa, 24(3), 1-24.

Pérez Gómez, A. I., Soto, E. y Serván, M. J. (2015). Lesson Studies: re-pensar y re-crear el conocimiento práctico en cooperación. Revista Interuniversitaria de Formación del Profesorado, 84(29.3), 81-101.

Pérez Gómez, A. I. y Soto, E. (2021). Aprender juntos a vivir y explorar la complejidad. Innovación pedagógica en tiempos de pandemia. Metodología y evaluación. Revista REICE. Revista Iberoamericana sobre Calidad, Eficacia y Cambio en Educación, 19(4).

Pérez-Henao, H. (2014). El lugar de la estética en la vida diaria: historia del concepto de estética cotidiana. Kepes, 10, 227-248.

Polanyi, M. (1967). The Tacit Knowledge Dimension. Routledge \& Kegan Paul.

Pozo, J. I, Scheuer, N., Mateos, M. y Pérez Echevarría, M. P. (2006). Las teorías implícitas sobre el aprendizaje y la enseñanza. En N. Scheuer, J. Pozo, M. P. Pérez Echevarría, M. M. Mateos Sanz, E. Martín Ortega y M. De la Cruz (Coords.), Nuevas formas de pensar la enseñanza y el aprendizaje. Las concepciones de profesores y alumnos (pp. 95-132). Graó.

Read, H. E. (2011). Al infierno con la cultura. Ediciones Cátedra.

Riera Jaume, M. A. (2005). El espacio-ambiente en las escuelas de Reggio Emilia. Indivisa, Boletin de Estudios e Investigación, 3, 27-36.

Riera Jaume, M. A., Ferrer Ribot, M. y Ribas Mas, C. (2014). La organización del espacio por ambientes de aprendizaje en la Educación Infantil: significados, antecedentes y reflexiones. Revista Latinoamericana de Educación Infantil (RELAdEI), 3(2), 19-39.

Rodríguez Arocho, W. C. (1999). El legado de Vygotski y de Piaget a la educación. Revista Latinoamericana de Psicología, 37(3), 477-489.

Saito, Y. (2007). Everyday Aesthetics. Oxford University Press.

Schön, D. (1994). The Reflective Practitioner: How Professionals Think in Action. Routledge.

Soto, E., Serván, M. J., Pérez Gómez, Á. I. y Peña Trapero, N. (2015). Lesson study and the development of teacher's competences: From practical knowledge to practical thinking. International Journal for Lesson and Learning Studies, 4(3), 209-223.

Soto, E., Maldonado-Ruiz, G., Márquez-Román, A. y Peña, N. (2021). Reconstruyendo el conocimiento práctico en confinamiento. Una experiencia de enseñanza en la formación inicial de docentes. Revista de Educación a Distancia (RED), 27(65), 1-39.

Stake, R. (2010). Qualitative Research: Studying How Things Work. Guilford Press.

Stenhouse, L. (1980). The Study of Samples and the Study of Cases. British Educational Research Journal, 6(1), $1-6$.

Taylor, S. y Bogdan, R. (1994). Introducción a los métodos cualitativos de investigación: La búsqueda de significados. Paidós.

Trueba, B. (2015). Espacios en armonía. Propuestas de actuación en ambientes para la infancia. Octaedro. Vecchi, V. (2013). Arte y creatividad en Reggio Emilia. El papel de los talleres y sus posibilidades en educación infantil. Morata. 